\title{
A Virtual Choir Ecology and the Zoom-machinic
}

\section{Visual Technologies as a Panacea for Social Isolation}

\author{
Kathryn Grushka \\ Dr \& Senior Lecturer, University of Newcastle, Newcastle, Australia \\ kath.grushka@newcastle.edu.au \\ Miranda Lawry \\ Dr \& Conjoint Senior Lecturer in Arts Health, School of Health Sciences, \\ Faculty of Health and Medicine, University of Newcastle, Newcastle, \\ Australia \\ miranda.lawry@newcastle.edu.au
}

\author{
Kim Sutherland \\ Order of Australia Medal holder \\ Musical Director of the Song Sisters \\ Musical Director of the Hunter Singers \\ New South Wales Department of Education, Newcastle, Australia \\ kim.sutherland@ozemail.com.au
}

\author{
Charissa Fergusson \\ Secondary School Music Educator, New South Wales Department of \\ Education, Newcastle, Australia \\ charissa.ferguson@det.nsw.edu.au
}

\begin{abstract}
COVID-19 has changed the way we sing in choirs and has seen the extraordinary uptake of Zoom as a video chat platform across society. This is a reflective tale of four choirs members and their insights into how they improvised with traditional choir singing in a Zoom space. It consideres how zoom pedagogies allowed them to bridge social isolation during the pandemic. It includes the voices of the conductor; music teacher/technician; the voice of a media savvy artist choir member and finally the voice of a singing visual educator. The article embeds Deleuzoguattarian thinking. It draws on the concepts of the machinic assemblage and becoming as choir participants who embraced


Zoom to facilitate song. Singing in a zoom virtual choir brings forth a burgeoning new relational way of being. To find ways to sing and imagine life and self without physical, temporal and spatial borders.

\section{Keywords}

visual technologies against social isolation - virtual choir - machinic autopoiesis - zoom ecology - Deleuzoguattarian thinking - becoming virtual

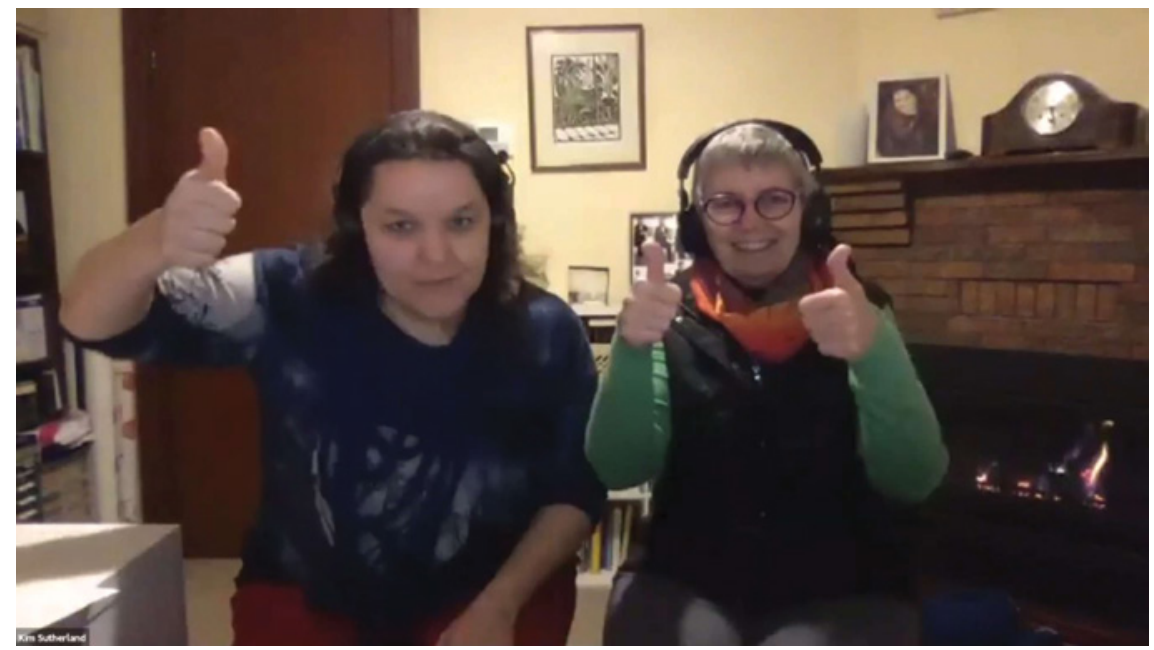

FEATURE This article comprises two videos, which can be viewed here.

- This article is part of the special topic 'Visual Technologies as a Panacea for Social Isolation', edited by Rene Novak.

\section{Introduction}

COVID-19 has changed and intensified the way individuals communicate virtually within society. Lockdown has seen an extrordinary up take of all online platforms including Zoom and other video chat platforms. Choirs, like the rest of society, out of necessity, have increasingly taken up these visual technology solutions. The web is now awash with stories about the ingenuity of choir teachers and singers using video technologies to connect to one another globally and in local communities (Shaw, 2020). This article is a tale of four choirs members of the Song Sisters and their combined insights into becoming a 
Zoom choir, in Nsw, Australia. The authors recount and reflect on how knowing self through zoom singing would shift the choir members collective identities. It discusses identity shifts through the idea of sense making as experience within a virtual choral ecology. It reveals how the choir adapted and evolved within this new techno reality. The author voices present different perspectives and connect later to demonstrate how together the conductors and choir members evolved their own visual pedagogies of Zoom. Kathryn Grushka is a visual arts educator/artist and researcher who draws together the research threads, Miranda Lawry is an arts health researcher and artist photographer, who understands the importance of continuing to sing together for learning and wellbeing benefits. Kim Sutherland a national choir conductor with an international profile and Charissa Fergusson an accomplished musician, teacher and musical technician. This article will consider how we might think about Zoom as an ecology where visual pedagogies are central to a virtual choir. The voices offer insights into the pre-COviD world of the choir and its post covid realities as the pre-digital choir learners demonstrate their resourcefulness and capacity to adapt, shift their identities, live, communicate and share their new digital lives.

\section{Song Sisters Choir: Becoming Virtual in a Machinic Ecology}

The 27 members of the Song Sisters were already believers in the power of singing together pre-COVID-19 and being a choir member was an defining element of their identities. As choir members they had come to understand that choral singing was special for them, both in terms of the constituted elements of their individual and collective social, mental and health ecology and the special place of music and performance in society (Dissenayake, 2014, 2009). Ecologies has emerged as a term to describe how subjectivities or identities evolve within complex living and adapting social systems. It draws on the original theoretical work of Maturana \& Varela (1980) who talk of autopoiesis within a biological domain. Autopoeisis presents living as sense making and experience that brings forth value into ones existence. Autopoeisis is a condition of all life and is constituted within a living machine where many domains of interaction operate as both a circular and self-referentially organized ecology (Thompson, 2004). Guattari (1995) extends this theory beyond the biological; to talk of autopoeisis as 'a machinism that has technological, social, semiotic and axiological avatars' (p. 34). These diverse relationships are not closed and must continuously undertake replacement of its components according to external forces in order to adapt. He goes beyond the idea of subjectivity or being as operating within a unique experiencing biological system 
(mind and body) to its complex constitution dependent on 'an ensemble of conditions' (p. 9) with traversality (Guattari, 2015). Chagas (2005) speaks to this idea as a virtual polyphony and embodiment of sound, aural perception and music as autopoiesis.

An 'ensemble of conditions' thus has a relational dynamic within a collective of structural complexities such as architectural spaces, economic relations, social structures, communication, technologies and cultural activity etc. An 'ensemble of conditions' is presented as a 'machinic assemblage' (p. 41) and is an ecology in which human action and intelligence are involved as they interact with all the components of the ensemble. This ecology is dynamic, it generates multiple subjectivities which continuously fold from the inside to the outside and vice versa with many possibilities (Deleuze, 2006).

For Guattari (1995) the machinic ecology also includes a montage of all preexisting components, such as knowing self as a choir member and performing in concerts pre covid. All are swept up into a new machinic autopoiesis as being becomes transversal (p. 38) as we move between and across our ever evolving identities, including being a choir member. Technology and communication now offers up an increasing array of possibilities within the virtual spaces of society. Zoom visual pedagogies draws on edusemiotics or a bricolage of different semiotic codes in order to create a new learning culture (Semestsky, 2019). For Born (2005) a musical assemblage has a "particular combination of mediations (sonic, discursive, visual, artefactual, technological, social, temporal) and is characteristic of certain musical cultures and historical periods" (p. 8). These ideas combine in a new assemblage zoom virtual choir.

A zoom choir is now driven by the digital and virtual phenomenon of webbased video conferencing tools. They are reshaping past machinic assemblages and they increasingly have a telepresence that is infiltrating across all society (Kei Kato \& Ishiguro, 2011). These ideas speak to what Braidotti calls the digital chat platforms capacity to carry nomadic interconnections (Braidotti, 2017). For Guattari (2015) it is the phenomenon of transversality operating within what Guattari calls machinic autopoiesis (1995).

Pedersen (2020) writing on digital music as an ecology of thinking also draws on the thinking of Deleuze and Guattari (1987) speaking of digital music as an assemblage of potentialities, potentialities that assemble and entangle informing ones identities as being and becoming, through past, present and future imaginings. Virtual choirs perform within their own ecology accessing the personal, the biological, and the technological. A virtual choir can harness sound-reproduction technology (recording and digitally manipulating), employ sound composers and together they constantly create new musical assemblages (conductor, sound technicians, singers) who are also user-listeners. 
The participants in the virtual choir understand that they are the energy of the assemblage, a virtual choir is not static but can disrupt its own articulations and put them together in new ways. Each virtual choir rehearsal has the potential to disrupt all previous learning moments in the continuous articulation of their new sound, becoming a virtual choir.

\section{The Move to an Online Virtual Reality}

In their pre coviD-19 world the choir members had drawn significantly on the social ecology of the choir as a system providing aesthetic experiences generated through the act of singing and being together, making song as one, building friendships and gathering support. The Song Sister choir members all have experience of far more than the linguistic signifiers within a song or the development of friendship and belonging. They understood the significance of the choir identity within the multiplicity of their subjectivities (Deleuze and Guattari, 1987).

For the resilient pre-digital singers COVID-19 became a reality as their lives moved online (Conger \& Griffith, 2020). The lockdown experience emerged as a period of personal uncertainty and anxiety about how they could sustain choir membership, singing and connecting through song. The Song Sisters Choir, was a reformed choir. Communication over those months leading up to the new choirs start date was primarily by messenger. Those who did not have Facebook or a digital device soon acquired one and the associated skills. This platform provided all the women (27) with a direct and responsive communication to support those who felt isolated and missing their choir. This was the first foray into the choirs digital new world, it was not to be the last.

Simultaneously music also appeared throughout the pandemic lockdown as a way for people to communicate and to break the long silences locked down in apartments and houses across the world. The internet filled with videos showing operatic performances from balconies in Italian villages, an entire street out on their verges singing daily or weekly. In an article from the Guardian from April $6^{\text {th }} 2020$ it describes how music has fought pandemics for 2,700 years: https://www.theguardian.com/music/2020/apr/06/stayin-alive -how-music-fought-pandemics-2700-years-coronavirus.

The Song Sisters choir members began posting songs and videos of choirs performing from across the globe. Once the lockdown really took effect Messenger became a very positive and engaging platform for daily contact, jokes, emojis, photos, links to articles and videos. It was like a surprise each day to 
harvest the messages. This connection through the messaging app built an enduring friendship network. For some women connection to Facebook (which became our communication stream) was a new experience. The predigital choir members now had access to a curated world of singing, choirs, performance and funny moments along side texts and links to music downloads etc. but how were they going to sing together?

My experience as a choral director has mostly been with primary and high school aged young people, particularly with Hunter Singers (1989-2019). For the past four years I have been engaged as a conductor for the Gondwana National Choral School, conducting Gondwana Novus, a choir of around $5^{0}$ young people aged $13^{-15}$ years. Adjusting to working with the Song Sisters was always going to take time as I needed to learn what the group was capable of, how they liked to operate, and what approach they needed during each 2 hour rehearsal. My understanding of the group was that they were a group of mostly older women who: loved to sing; enjoyed the friendships and socialisation within the group; valued the wellbeing created by the joy of singing; felt energised and uplifted by singing beautiful music.

I tried to select repertoire which would be both challenging, and achievable. I recognised the importance of singing for the women and was just starting to see how much they benefited from the structured physical and cognitive aspects of the rehearsals such as:

- Physical warm ups, breathing and gentle movement

- Vocal warm ups including humming, range extension, aural awareness, tongue twisters and something to extend the brain

- Up to three songs involving part by part unison rehearsal, 2-part harmony work leading to 3 or 4 part harmony, and revision of a song from the last rehearsal

- A break in the middle of the rehearsal for socialisation

I felt that I was starting to get a grip on the rehearsal structure, when covid-19 forced the choir into working in a completely different way. I immediately lost the hold I was gaining on understanding myself as a adult womens conductor rather than a conductor of children. Alarming reports from the USA ment it would be sometime before we could meet again in the same physical space (https://www.theconversation.com/this-video-shows-just-how-easily-covid -19-could-spread-when-people-sing-together-144789). We had had only four 
rehearsals, there would be no more face-to-face rehearsals. I had been toying with the idea of introducing Zoom rehearsals but didn't know if it would work; not only was the technology new to me, I knew that the members of Song Sisters might struggle with being able to access rehearsals.

As my first foray into providing something a bit different I recorded a rehearsal on Youtube on the 27 March, 2020 and posted it on the Song Sisters Facebook page (see Video 1).

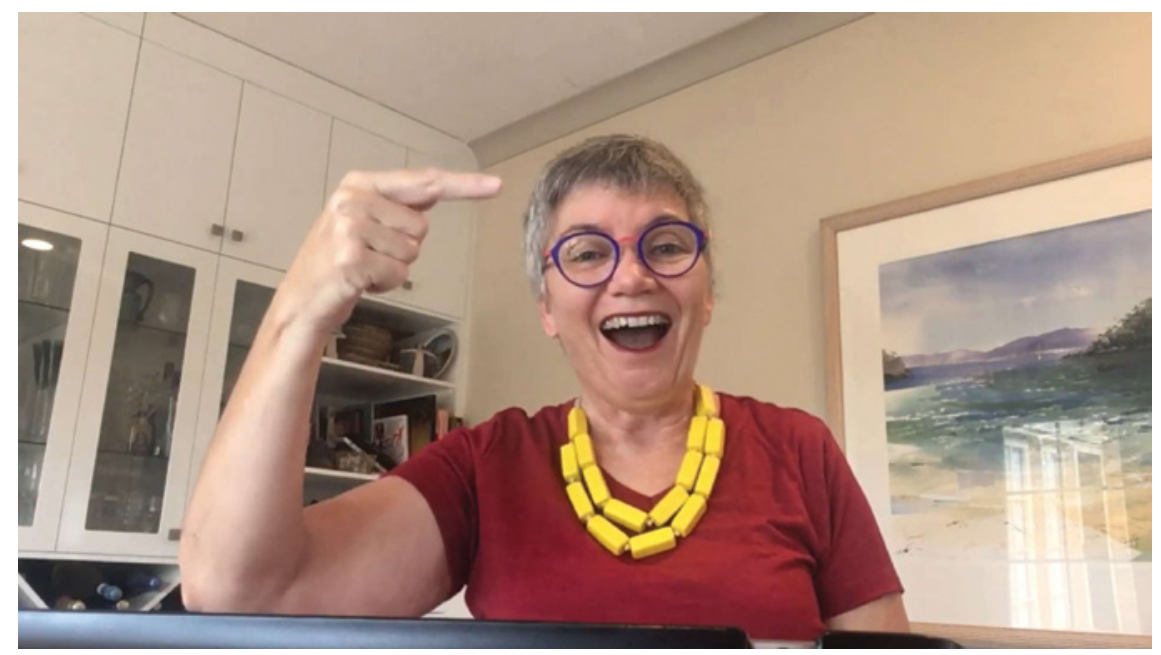

VIDEO 1 Song Sisters first online rehearsal encounter. (See here and here.)

This received good feedback from the choristers, although it was virtual with new temporal and spatial experiences. They could now access my session at any time on Yourtube, yet I felt uncomfortable with how it came across. I was unsure whether my teacher pedagogies were appropriate for this virtual space. I had suddenly gone from being an experienced conductor to a novice trying to conduct via video and run an engaging rehearsal! I was now bridging the spaces between being a conductor of women and a digital virtual mediator, teacher and communicator.

I was now very keen to give Zoom a try if the members would like to come on board. My Gondwana colleagues spoke positively about the Zoom experience and the impact it was having on their choirs as well as its world wide impact. But I had yet to feel comfortable on the journey to becoming a zoom choir conductor. This was unfamiliar territory and my professional identity was about to experience a significant social and technological adaption. 
A world of seeing and being as a virtual phenomenon has now become integral to how we globally participate in choirs. Current research is focusing on being an isolated body with united voices, the pedagogy of Zoom, musicianship, collaboration and community-building prospects of virtual choirs in the age of covid-19 (Galvan \& Clauhs, 2020; Sublet, 2020). Diana Kuls's (2020) Virtual Choirs Research has identified that zoom choirs bring additional benefits to traditional choirs. In Figure 1 this extract from her data identifies that the opportunity to participate regardless of where you live is the biggest advantage of Zoom for a virtual choir. Secondly it can generate a new sense of community, continue to do voice development and opened up the world to the new concept of Virtual Choirs.

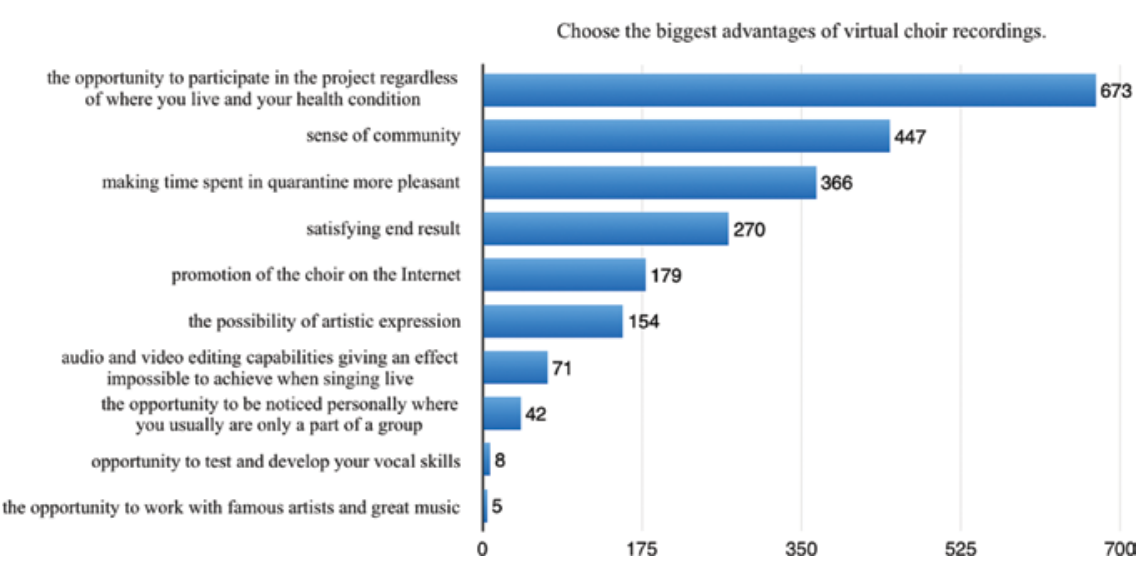

FIGURE 1 Kuls Virtual Choirs Research (2020)

The zoom telepresence for Song Sisters was providing the opportunity to talk about how they felt in isolation, but would it be a good subsititute for singing together beside one another?

\section{Becoming a Virtual Choir: Journeying through the Eyes of the} Conductor

We held our first Song Sisters Zoom rehearsal with me as conductor in April, 2020. There were key differences. I now had a technical musician as an assistant. She operated the screen sharing, controlled the audio and fielded 
questions from the chat room and participated in the singing. This was a first step in becoming a machanic assemblage, bringing together a range of music technolgies and ways of knowing onto a zoom platform.

The initial set up involved a Rodecaster Pro sound desk with two Rode dynamic microphones, a laptop computer connected to a larger monitor so we could operate two screens, a roll up keyboard and an iPad with the vocal warm ups. We set up all the music and the audio in advance so that the rehearsal would run as smoothly as possible (see Figure 2).

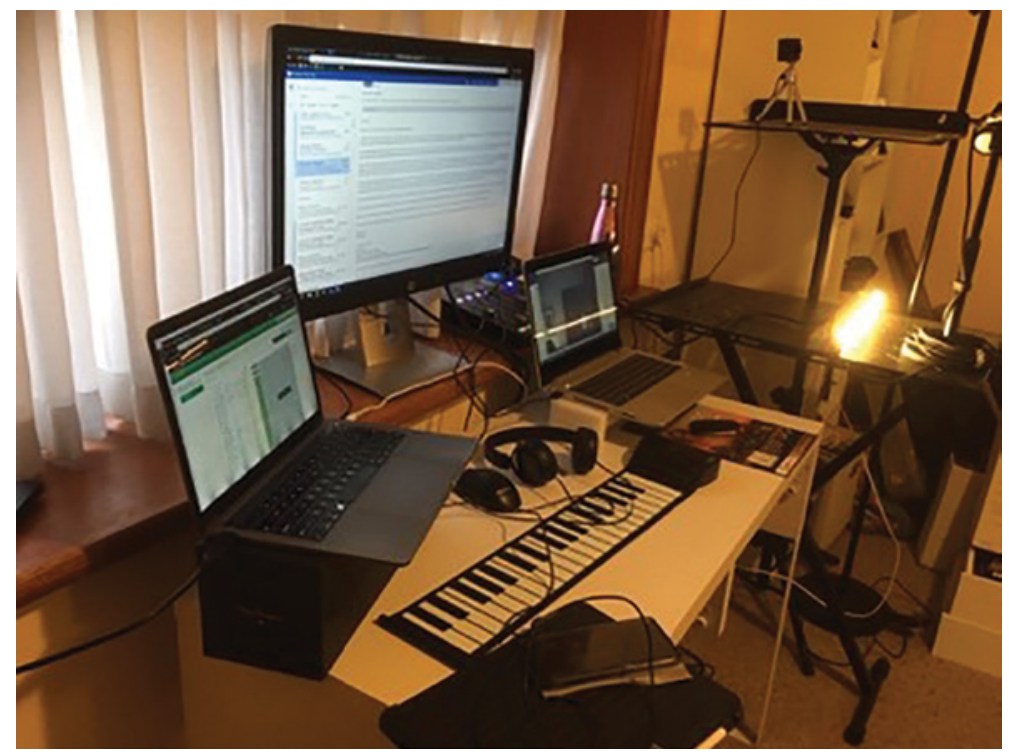

FIGURE 2 Zoom Music studio set up 1

We later upgraded the set up to a full keyboard and a Rode condenser microphone for better sound quality. An unforeseen advantage of the condenser microphone was that choristers found it easier to follow what I was doing as they could see my mouth, which had previously been hidden by the dynamic microphone. (See Figure 3.)

I structured each 6o-minute Zoom session to have the same structure as a face-to-face rehearsal, but there were obvious limitations to the experience for the choristers, the biggest one being that they couldn't hear each other! (See Video 2.)

At the first rehearsal I didn't know how many of the group would 'turn up' so it was a lovely surprise to find face after face appearing on the screen until there were around 20 participants from different locations coming together 


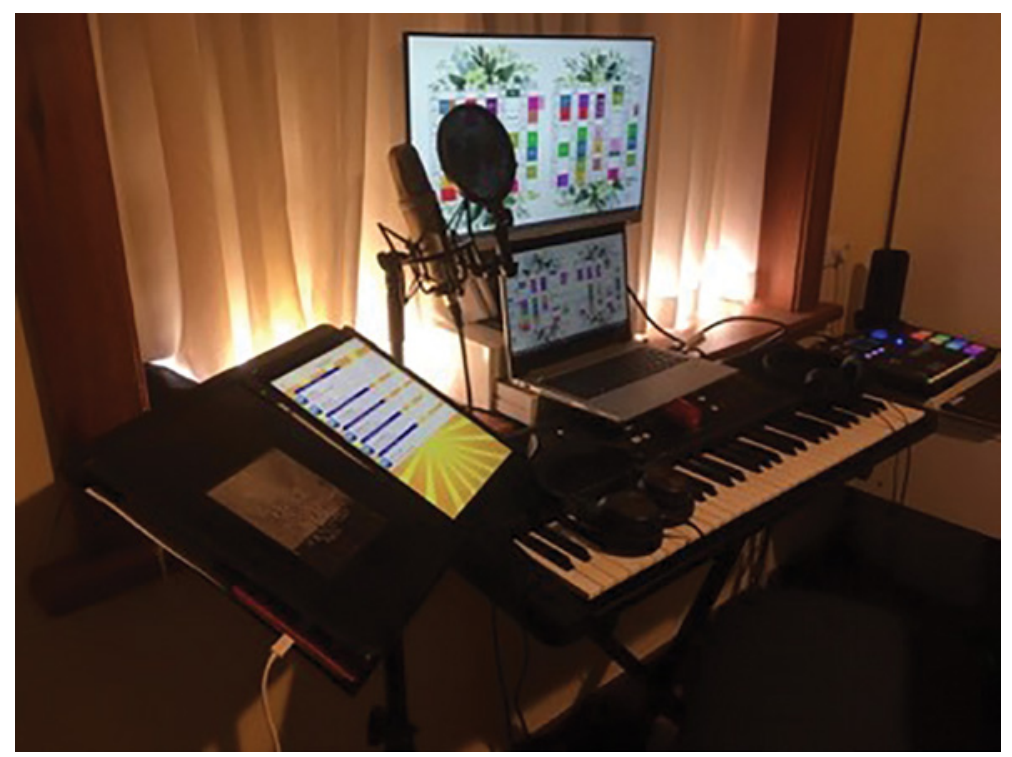

FIGURE 3 Zoom Music studio set up 2

with a virtual presence. I initially focused on the wellbeing aspect of the choir talking together about isolation. Although this took some time, it was valuable for the members to see and hear each other and to check in with each person's circumstances. There was understandable anxiety, especially from those who had loved ones overseas in London and New York. It was also a good opportunity for me to get to know everyone a little better. We had after all only seen each other on four occasions, and I had not yet had the chance to have a conversation with each person. Following the chat we did some warm ups and sang two songs.

While improvement was a given, the group was positive so we determined that the Zoom rehearsals would continue. But we were a very insecure group all learning together, musically and technically

As the choir evolved new challenges were possible. I recommended to the group that we all participate in Eric Whitacre's Virtual Choir 6. A virtual choir is a very different beast to a Zoom rehearsal. It involves each participant learning a song with a backing and teaching track and then videoing the song while wearing headphones and uploading the video to an online link. The song, Sing Gently, was not too challenging to sing, however doing the video required a whole new skill set. After some experimentation I suggested a set up where you could read the music and see the conductor on one device, while recording the 
video on another device such as a smartphone. The settings on the phone had to be set to a lower resolution, so this was something else that the choristers had to deal with. We rehearsed both the soprano and alto parts in the Zoom rehearsal to familiarise the group with the music. Some choristers had to really extend their technology skills in order to participate and I was thrilled to see so many taking up the rather daunting challenge. Some members of Song Sisters became members of a global Virtual Choir performing internationally (https:// www.youtube.com/watch?v=InULYfJHKIo). 17,572 singers from 129 countries.

As we continued the Zoom rehearsal shifted to a joint presentation between the musician singer/technican and the conductor working together. To run a Zoom rehearsal we needed two operators to change the dynamic and the energy of the Zoom sessions. In each Zoom rehearsal we continued to refine and improve the approach to the rehearsal, and gradually began to relax into a more comfortable presentation. But we were still limited by the fact that the choristers couldn't hear each other, but they could at least learn parts of the repertoire and sing along to an existing recording.

After a few weeks we experimented with recording tracks into Audacity as the rehearsal progressed, and layering up the parts so that on playback the group was hearing all parts sung by the joint presenters. This improved the chorister experience as they could now hear more than one part at a time. It was significantly more complicated from an operational perspective, but worth the extra effort as we could see that the singers were more engaged in their participation. We also received feedback from the group that it was easier to sing along.

As conductor, I found the Zoom sessions to be quite limiting as there was no opportunity to work on the sound of the choir. However, the ability to focus on learning parts may prove to be valuable when we are finally able to be a choir again. For now we will continue to present rehearsals on Zoom as the future is still unknown. At this point in time there is a confidence, a more relaxed engagement with the technology and friendships and the joy of singing continues.

The Song Sisters now had a telepresence that had meaning for them even with its limitations (Martinec, 2020). They are part of the web which is a wash with stories of how choirs are using visual technologies to connect to one another globally. They are also a part of the research that continues to demonstrate its benefits to to mental and physical health of the virtural performers (Daffern, et al., 2019). In the local community the Song Sisters are part of that story 'Singing lifts Hunter choir's spirits in isolation' (Gregory, 2020: https://www.newcastle herald.com.au/story/6807894/singing-lifts-hunter-choirs-spirits-in-isolation). 
Deleuzoguattarian thinking acknowledges that human identities are not fixed but multiple and connected to social intuiting acts. Both Deleuze and Guattari challenge existing logic about sense making, its empirical roots and binary constructs, in favour of intuition and creative transdisciplinary/technological learning. Visual pedagogies are embodied and constructed relationally across varied experiences. An identity or being. is therefore affectively triggered: "a subject will be what comes to the point of view, or what rather contains the point of view" (Deleuze, 2006, p. 21). In new Zoom social spaces being and singing can shift us beyond the actual known physical choir to recognizing that life has future imaginative potential forms via the virtual thus our identities and lives are always folding (Deleuze 1990) within an evolving ecology (Guattari, 1995).

Zooming has precipitated an acceleration from the idea that the mind is bounded in the human perceptual and sensing self (living machine) to acknowledging that subjectivities are now experiences in relationships with our eco-social self (Halsey, 2005) and the relationship between the digital, biological and technological self (Parisi, 2009). Guattari (2015) describes the self as capable of new enunciations or lines of flight beyond human interactions and events to the affects of the non-human (Guattari, 2015) and an emphasis on what he calls machinic autopoiesis (1995). Zoom technologies and their visual pedagogies providing the most recent significant impact of machinic autopoiesis on all members of society in the global covid-19 world reality.

Zoom and song as artistic acts now enter this picture and bring forth a burgening new relationship, a new way to consider how to overcome social distancing and find new ways to image life without physical borders. For the authors reflecting on the choirs' journey to the digital and virtual world of Zoom it is possible to see that the machinic assemblage is inseparable from changes in the material, cognitive and affective capabilities of a body to feel (Parisi, 2009 p. 182). The authors observed how the phenomenon of Zoom had the capabilities to unfold multiple subjectivities via innumerable resonances through audio-visual, video-tecephonic and mobile connection (Parisi, 2009).

The identity shifts of the choir as a whole acknowledge they are now part of a new way of seeing and knowing themselves individually and collectively. This emergent new choir identity was a journey with its ups and downs. Technical issues were ever present in the early stages of the choirs adventures online and singing had certainly lost much of the aesthetic and performing pleasure the choir members were used to. 


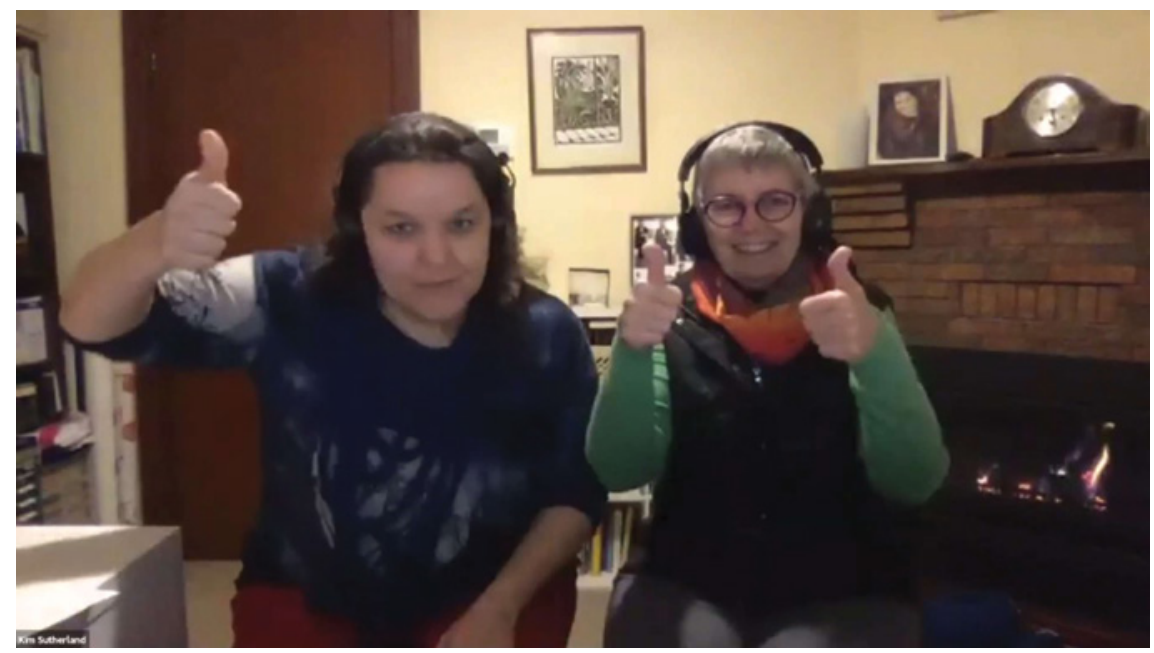

VIDEO 2 Performing as choir via zoom, the journey. (See here and here.)

In Video 2 you can watch two different phases of the Song Sisters' virtual becoming. Initially as they enter a virtual choral ecology and then as the video continues becoming virtual in a machinic ecology noted on September, 10, 2020. The final video section demonstrates evidence of a more relaxed group of singers who had shifted considerably and are now enjoying the best (all be it limited) that this new Zoom technology offers. During this pandemic period the choir has adapted to this new zoom ecology and been a part of Zoom's applications well beyond its original purpose as a conferenceing tool. Zoom singing as a choir voice assemblage now resides in what Prior (2018) calls a network of hybrid, multi-scalar, human-non-human events that emerge through nested constellations.

Sense making and experience, as being, brings forth value into ones existence (Deleuze, 2006). Singing and virtual choirs are now located in an ecology of human semiotic productions dependent on techno-logical machines of information and communication and the Zoom appartatus. Zoom is now at the heart of the identities of the Song Sisters. They are now inter-subjectively constituted through the telepresence zoom provides. This pre-digital choir is now defined by the social and individual actions, language and machinic apparatus of video, zoom and chat space technologies. Their identities as zoom chorasters operate from an existential node. In this virtual space the spiritual universes of reference such as music and the plastic arts can now operate (Guattari, 1992). 
This article speaks to the capacity of Zoom as a visual pedaogogy and multi modal choir technology to support the re-imagining of choral singing for well being. It has considered how a zoom choir can be seen as a machinic assemblage. It has demonstrated elements of the collective journey of the pre-digital choir members through the voices of the four authors. It provides evidence to sustain the idea that the Song Sisters have experienced a new burgening relationally in which Zoom pedagogies offer up a new way of being. Zoom pedagogies are a virtual space where singing supports the overcoming of social distancing and facilitiates new ways of knowing self. In the urgency of COVID-19 the singers found ways to adapt through what this article refers to as the zoom machinic, becoming through a new digital virtual choir ecology. The authors have considered the learning opportunities, journeying and possibilities that emerged for the choir members whose lives were ruptured by COVID-19 and lockdown. The zoom-machinic assemblage has significantly impacted on the Song Sisters subjectivity during COVID-19 and it has been a new watershed moment in choral singing globally and especially for the Song Sisters. They now grasp the extended idea that being physically distanced does not have to include social distancing and that a zoom-machinic assemblage accommodates new material arrangements via both the digital and vitural. While they still long to sing together, Zoom has offered up a new way to imagine life and self as a virtual choir member. Its impact has been profound and experiencing life as a zoom choir member allowed the emergence of new identities of self and other, new understandings of distance, locality, presence and how these relationships can be understood as always evolving within a Zoom-machinic, virtual choral ecology.

\section{References}

Attard, M. (2020). Ok Zoomer: how seniors are learning to lead more digital lives. May 22, The Guardian: https://www.theguardian.com/lifeandstyle/2020/may/o1/ ok-zoomer-how-seniors-are-learning-to-lead-more-digital-lives.

Born, G. (2005). On Musical Mediation: Ontology, Technology and. Creativity. twentiethcentury music, 2 (1), 7-36. doi:10.1017/S147857220500023X.

Braidotti, R. (2017). Memoirs of a PostHumanist. Tanner Foundation Lecture. Yale University. https://tannerlectures.utah.edu/Manuscript\%2ofor\%2oTanners\%2oFoun dation\%20Final\%20Oct\%201.pdf. 
Chagas, P. C. (2005). Polyphony and embodiment: a critical approach to the theory of autopoiesis. Trans. Revista Transcultural de Música, núm. 9, diciembre, 2005. https://www.redalyc.org/articulo.oa?id=82200915.

Conger, K. \& Griffith, E. (2020). As Life Moves Online, an Older Generation Faces a Digital Divide. The New York Times, March 27.

Daffern, H.; Camlin, D. A.; Egermann, H.; Gully, A.j.; Kearney, G.; Neale, C. \& Rees-Jones, J. (2019). Exploring the potential of virtual reality technology to investigate the health and well being benefits of group singing. International Journal of Performance Arts and Digital media, 15(1), 1-22.

Deleuze, G. Guattari, F. (1987). A Thousand Plateaus: Capitalism and Schizophrenia. London: University of Minnesota Press.

Deleuze, G. (1993/2006). The Fold: Leibniz and the Baroque (Trans. T. Conley), Minneapolis: University of Minnesota Press.

Dissanayake, E. (2009). The Artification Hypothesis and its Revevance to Cognitive Science, Evolutionary Aesthetics and Neuraesthetcis, (5), 148-173.

Dissanayake, E. (2014). A Bon Fide Ethology View of Art: The Artification Hypothesis, In Art as Behaviour: An Ethological Approach to Visual and Verbal Art, Music and Architecture (2014), eds. Christa Sütterlin, W. Schiefenhövel, Christian Lehmann, Johanna Forster and Gerhard Apfelauer. Vol. 10 Hanse Studies, BIs-Verlag der Carl von Ossietzky Universität Oldenburg, pp. 43-62.

Galvan, J. Clauhs, M. (2020). The Virtual Choir as Collaboration. Choral Journal, 6r(3), $10-18$.

Guattari, F. (1995). Chaosmosis: an ethico-aesthetic paradigm. Sydney: Power Publications.

Guattari, F. (2015). Transdisciplinarity Must Become Transversality. Theory, Culture and Society, $3^{2}$ (5-6 Special Issue: Transdisciplinary Problematics), 131-137. doi:10.1177/0263276415597045.

Gregory, H. (2020, 8/06/2020). singing lifts hunter choirs spirits in isolation, newspaper Newcastle Herald. Retrieved from https://www.newcastleherald.com.au/story/ 6807894/singing-lifts-hunter-choirs-spirits-in-isolation/.

Halsey, M. (2005). Ecology and machinic thought: Nietzsche, Deleuze, Guattari ANGELAKI: journal of the theoretical humanities, 10(3), 33-55. doi:10.1080/09697250 500423017 .

Kei Kato, H. N. Ishiguro, H. (2011). Zoom Cameras and Moveable Displays Enhance Social Telepresence. Paper presented at the cc!, Vancouver, British Columbia. https:// dl.acm.org/doi/pdf/10.1145/1978942.1978953.

Kuls, D. (2020) Report on Virtual Choirs Research: Singing in a virtual choir during global pamdemic-limitation or new possibilities? The Fryderyk Chopin University of Music.

Matura, H. R. Varela, F. J. (1980). Autopoeisis and Cognition: The Realization of the Living. (Vol. 42). Dordrecht: D. Reidel. 
Martinec, J. (2020). The Virtual Choir: Examining the Benefits and Obstacles of Online Teaching in the Choral Setting. Musicien Educateur Au Canada, 41-46.

Parisi, L. (2009). Technoecologies. In B. Herzogenrath (Ed.), Deleuze|Guattari \& Ecologies. New York: Palgrave Macmillan.

Pedersen, A. H. (2020). Digital Music use as Ecological Thinking: MetaData and Historicised Listening. The Nordic Journal of Aesthetics, 59, 97-11.

Prior, N. (2018). On Vocal Assemblages: From Edison to Miku. Contemporary Music Review, 37(5-6) , 488-506. https://www.doi.org/10.1080/07494467.2017.1402467.

Semetsky, I. (2019). Visual Semiotics and Real Events, Visual Journal of Education and Pedagogy, 1-21. https://www.doi.org/10.1163/23644583-00401006.

Shaw, J. T. (2020). covid-Era Music Education: What Choral Teachers Can Carry Forward. Choral Connections, $5^{-7}$.

Subet, A. (2020). Virtual Choir Practice: 'Singing in dark times we can turn our voices to the light'. Retrieved from https://www.theguardian.com/lifeandstyle/2020/apr/01/ virtual-choir-practice-singing-in-dark-times-we-can-turn-our-voices-to-the-light.

Thompson, E. (2004). Life and mind: From autopoiesis to neurophenomenology. A tribute to Francisco Varela. Phenomenology and the Cognitive Sciences 3, 381-398 (2004). https://www.doi.org/10.1023/B:PHEN.0000048936.73339.dd. 